\section{O cotidiano de adolescentes em um Centro de Atenção Psicossocial de Álcool e outras Drogas: realidades e desafios}

\author{
The daily routine of teens at a Center for \\ Psychosocial Care for Alcohol and Other \\ Drugs in Brazil: realities and challenges
}

\section{El día a día de los adolescentes en un Centro de Atención Psicosocial de Alcohol y otras Drogas en Brasil: realidades y desafíos}

Carina Curti Galhardi 1

Thelma Simões Matsukura

\title{
Resumo
}

Este estudo objetivou compreender o cotidiano dos adolescentes em relação às drogas, no Centro de Atenção Psicossocial de Álcool e outras Drogas (CAPSad) e nos demais contextos de inserção pelos quais transitam, sob a ótica dos próprios adolescentes. Contou-se com a participação de oito adolescentes com idades entre 12 e 18 anos vinculados ao CAPSad, de um município de médio porte no interior do Estado de São Paulo, Brasil, onde o estudo foi realizado. Para a coleta de dados utilizou-se um formulário de identificação dos adolescentes e rede familiar e um roteiro de entrevista semiestruturada. Para a análise dos dados adotou-se a técnica do Discurso do Sujeito Coletivo (DSC). Os resultados evidenciam que os adolescentes vivenciam um processo de exclusão social e desengajamento em diversas esferas da vida e destaca o CAPSad como um espaço importante no dia a dia, porém ainda limitado nas ações de atenção e cuidado aos adolescentes. Este estudo acrescenta ao dar voz aos adolescentes, população que frequentemente está excluída dos serviços destinados ao acolhimento e tratamento do uso de drogas, como também ao identificar e compreender sobre as drogas e as particularidades de seus cotidianos, segundo suas próprias perspectivas, dentro e fora do serviço.

Drogadição; Atividades Cotidianas; Saúde Mental; Adolescente

\author{
Correspondência \\ C. C. Galhardi \\ Av. Dr. Adhemar Pereira de Barros 54, Araraquara, SP \\ 14807-040, Brasil. \\ carinacurti@hotmail.com \\ 1 Universidade Federal de São Carlos, São Carlos, Brasil.
}




\section{Introdução}

Há uma estimativa que entre $10 \%$ e $20 \%$ da população mundial de crianças e adolescentes sofram de transtornos mentais e cerca de $3 \%$ a $4 \%$ precisam de tratamento intensivo. Aponta-se, ainda, um aumento do suicídio e do uso de drogas entre adolescentes 1 .

Sobre o uso de drogas, destaca-se que os adolescentes estão mais vulneráveis, pois é nesta fase da vida que se busca vivenciar e explorar com mais intensidade as descobertas e identificações, geralmente realizando associações aos grupos 2 .

Estudos têm identificado que o uso de drogas inicia-se precocemente e a idade do primeiro uso tem sido geralmente de 12,5 anos para álcool; 12,8 para tabaco; e para as drogas ilícitas, como maconha e cocaína, por exemplo, o primeiro uso tem ocorrido, em média, aos 13 anos 3,4.

Mais especificamente ao uso de drogas, as primeiras ações do governo brasileiro aconteceram no início do século XX com a elaboração de um aparato jurídico institucional que pretendia proteger a população e controlar o uso e venda de drogas, sendo promulgado, em 1938, o Decreto-Lei no 891, posteriormente introduzido no Código Penal de 1941, que ratifica diversas substâncias psicoativas como ilícitas e também determina a toxicomania como doença de notificação compulsória. As premissas presentes no código penal foram sustentadas por três décadas e incentivaram as ações de repressão ao tráfico e ao consumo de drogas 5 .

Essa forma repressiva de organizar as ações relacionadas ao tráfico e consumo de drogas, visando ao combate e abstinência, foi denominada de política de "guerra" às drogas. Esse modelo foi incorporado pelo Brasil e teve forte influência nas intervenções aos usuários de drogas, as quais em grande parte eram aplicadas de forma violenta e estigmatizante 6.

Foi também a partir do século XX que a infância e adolescência passaram a ser focalizadas, como consequência das repercussões ocasionadas pela consolidação da Medicina como ciência, da Psiquiatria e pelas intervenções do movimento higienista, mesmo que alicerçadas em práticas baseadas na disciplina e punição ${ }^{7}$. Na década de 1980, período de abertura democrática no país, os movimentos sociais, como o movimento sanitário e o movimento dos trabalhadores de saúde mental, estavam se consolidando e viabilizaram uma discussão mais ampliada em relação à atenção em saúde mental, sob o enfoque da reabilitação psicossocial 8 .

Assim, após um longo caminho, em 1990 institui-se o Estatuto da Criança e do Adolescente (ECA), pela Lei no 8.069, que veio anunciar uma nova concepção da infância e adolescência, com base na perspectiva da prioridade absoluta, configurando-os como sujeitos de direitos e em condição peculiar de desenvolvimento 9 .

Não obstante, apesar dos avanços, a elaboração de políticas públicas e estratégias de cuidado destinadas à população infanto-juvenil no âmbito da saúde, incluindo o uso abusivo de drogas, ganharam foco apenas no final de 2001, na III Conferência Nacional de Saúde Mental 1,6. No entanto, apenas em 2009, a temática relacionada ao uso de drogas por crianças e adolescentes foi tema central do Fórum Nacional de Saúde Mental Infanto-juvenil, apontando-se com base nos debates, diretrizes para o cuidado, maneira de organizar a rede para atender estes sujeitos e, por último, questões sobre o sistema socioeducativo e drogadição 10 .

Em relação ao conjunto de serviços destinados à população infanto-juvenil com necessidades decorrentes do uso de álcool e outras drogas, tem-se os Centros de Atenção Psicossocial Infanto-juvenis (CAPSi) e os Centros de Atenção Psicossocial de Álcool e outras Drogas (CAPSad), os quais oferecem atendimento a adultos e/ou adolescentes com necessidades decorrentes do uso de drogas 1,11. Importa ressaltar que segundo a Portaria MS/GM no 3.088 12, de 23 de dezembro de 2011, a qual estabelece a Rede de Atenção Psicossocial (RAPS) para pessoas com sofrimento ou transtorno mental e com necessidades decorrentes do uso de drogas, qualquer modalidade de CAPS pode acolher e realizar ações de cuidado às pessoas que necessitam de auxílio em relação ao uso abusivo de drogas, incluindo crianças e adolescentes, a depender da disponibilidade dos serviços no município e da dinâmica de atendimentos no mesmo 12 .

A RAPS propõe ainda que as ações de cuidado aconteçam de modo ampliado, sendo a interlocução entre os diferentes pontos de atenção da Rede a premissa do trabalho e um elemento potente e fundamental para a efetivação das intervenções 13 . 
As perspectivas relativas à compreensão e às proposições de intervenção que envolvem o uso abusivo de drogas também se expressam nas atuais pesquisas baseando-se em duas abordagens: uma pautada na abstinência, a outra, pautada na redução de danos (RD) 5,14,15,16,17,18.

A abstinência, como finalidade exclusiva do tratamento, pautada nas internações como prática, tem recebido críticas de diversas ordens em que, além dos questionamentos sobre sua eficácia, é apontada como retrocesso às práticas que se pretendeu superar a partir da reforma psiquiátrica e com princípios contrários aos preconizados pelas políticas públicas do setor 14,16,17,18.

Já a RD não adota a abstinência como pressuposto, sendo o seu principal objetivo minimizar os possíveis riscos advindos do uso abusivo de drogas. Suas premissas também envolvem a escuta, o acolhimento das singularidades e subjetividades da pessoa que esteja com problemas em relação ao uso abusivo de drogas, o autocuidado, autoconhecimento e participação ativa do usuário em suas ações de cuidado 16,17,18. Tal abordagem também é foco de discussões e pesquisas, nas quais revela-se, por exemplo, dificuldades na efetivação concreta da estratégia de $\mathrm{RD}$, pois alguns profissionais não estão capacitados; a prevalência no imaginário social apenas dos tratamentos "tradicionais" à pessoa que possui necessidades em relação à questão do uso de drogas, dentre outras 16,17,18.

A literatura aponta que há uma lacuna sobre onde os adolescentes estão buscando auxílio no que diz respeito às problemáticas relacionadas ao uso das drogas, sendo necessário dar foco a esta questão e realizar estudos que investiguem e aprofundem esta realidade, visto a importância e urgência que ela demanda $2,19,20$.

O trabalho de Raupp \& Sapiro 20 buscou analisar as modalidades de atendimento aos adolescentes que realizavam uso abusivo de drogas e eram encaminhados para a rede pública, a fim de avaliá-las baseando-se no que preconizam as políticas públicas valendo-se de entrevistas com os próprios adolescentes e com os profissionais dos serviços. Verificou-se no estudo que os profissionais ainda mantinham a perspectiva do uso de drogas como doença, não levando em consideração, muitas vezes, outras motivações para o uso, como também mantendo um olhar generalista desses adolescentes, sem se atentar para as subjetividades dos mesmos, apontando a necessidade de novos trabalhos que aprofundem em tal realidade.

A pesquisa de Araújo et al. 21 buscou identificar o perfil clínico e sociodemográfico de adolescentes que permaneceram e não permaneceram em tratamento entre os anos de 2009 a 2011 em um CAPSad de Cuiabá (Mato Grosso), com base em informações dos prontuários do serviço, e revelou que em ambos os grupos (dos adolescentes que aderiram e dos que não aderiram ao tratamento) houve predomínio de jovens do sexo masculino, de 15 a 17 anos, solteiros, com ensino fundamental incompleto, sem trabalho e que já tiveram envolvimento com a justiça. Os autores destacaram limitações no estudo por ter sido realizado por meio de dados dos prontuários, e reforçam a importância e necessidade de que novos trabalhos sejam realizados para melhor esclarecimento sobre essa população.

Baseando-se no exposto, compreende-se a demanda por aprofundar na compreensão do cotidiano e nas questões intrínsecas desses sujeitos a partir da ótica dos próprios adolescentes. Este estudo focaliza adolescentes usuários de álcool e outras drogas, tendo como pano de fundo o CAPSad e o cotidiano fora do serviço.

\section{Objetivo}

Este trabalho objetivou compreender o cotidiano dos adolescentes em relação às drogas, o CAPSad e os demais contextos de inserção pelos quais transitam, buscando dar voz aos adolescentes.

\section{Método}

Trata-se de um estudo exploratório, de abordagem qualitativa, em que foi utilizada como metodologia a observação participante, na qual o pesquisador realiza contato direito com o fenômeno investigado, inserindo-se no cotidiano do mesmo, com o objetivo de compreender a realidade vivenciada pelos atores sociais 22 . 
A pesquisa foi desenvolvida em um CAPSad, localizado em um município de médio porte do Estado de São Paulo. A escolha desse CAPSad foi por conveniência, pautada nos seguintes critérios: contar com programas e/ou atividades voltadas para a atenção de adolescentes e ter mais de três anos de funcionamento.

O estudo foi submetido e aprovado por Comitê de Ética em Pesquisa em Seres Humanos. Além disso, a Secretaria Municipal de Saúde de São Paulo e a coordenação do CAPSad autorizaram a realização do trabalho.

Participaram do estudo oito adolescentes com idades entre 12 e 18 anos, inseridos no CAPSad. Os critérios de inclusão para a participação dos adolescentes foram: ter idades entre 12 e 18 anos; aceitarem participar do estudo; estarem inseridos no serviço por, no mínimo, seis meses; e estarem vinculados ao mesmo por problemas relacionados ao uso de álcool e outras drogas (e não como motivação primária outras problemáticas relativas aos transtornos mentais).

Os instrumentos utilizados para a coleta de dados foram: um formulário de identificação dos adolescentes que buscou identificar características dos mesmos, estrutura familiar, dentre outras; e um roteiro de entrevista semiestruturada, que abordou sobre o cotidiano do adolescente dentro e fora do serviço, sobre o engajamento em atividades e relacionamentos, suporte e inserção social.

A pesquisadora permaneceu no serviço durante cinco meses (de janeiro a maio de 2015), todos os dias da semana, das 8 às 19 horas, período este considerado adequado para a apreensão e aprofundamento do objeto de estudo, com especial destaque para o vínculo desejável e necessário com os adolescentes.

Os adolescentes que aceitaram participar do estudo e tinham mais de 18 anos assinaram o Termo de Consentimento Livre e Esclarecido, já para os menores de 18 anos, o Termo foi assinado pelo familiar e o adolescente preencheu um termo de assentimento. A forma e horários para as entrevistas foram pactuados com os adolescentes e todas foram realizadas no CAPSad, em salas e espaços onde a privacidade fosse garantida.

Os registros das entrevistas semiestruturadas foram transcritos na íntegra e analisados pela técnica do Discurso do Sujeito Coletivo (DSC), desenvolvida por Lefevre \& Lefevre 23. A técnica do DSC é utilizada para organização e análise de dados qualitativos de natureza verbal e tem como fundamento a Teoria da Representação Social e seus pressupostos sociológicos, a qual defende que uma pessoa é ao mesmo tempo individual e coletiva, pois possui singularidades, mas também faz parte de uma coletividade 23 .

O objetivo do DSC é, por meio da análise do material verbal, construir um ou mais discursossíntese que expressem a coletividade, escrito na primeira pessoa do singular. Os discursos-síntese são construídos selecionando-se de cada resposta individual as expressões-chave, que são caracterizadas como fragmentos mais importantes das respostas, e também pelas ideias centrais, as quais são extraídas baseando-se nas expressões-chave ${ }^{24}$.

\section{Resultados e discussão}

Inicialmente serão apresentados os resultados sobre a caracterização dos participantes e, a seguir, os resultados e discussão advindos das entrevistas com os adolescentes, com base em três eixos.

\section{Caracterização dos participantes}

Apresenta-se na Tabela 1, a caracterização dos adolescentes participantes da pesquisa.

Com base nas informações apresentadas na Tabela 1, observou-se que a idade dos participantes variou de 12 a 18 anos, apenas quatro adolescentes permaneciam na escola e, em relação ao tipo de droga consumida, todos eles relataram já ter feito uso de maconha, cigarro e álcool. Esse padrão de consumo dos participantes é semelhante ao encontrado em pesquisas realizadas com adolescentes, em que as drogas de uso mais citadas pelos mesmos foram o álcool e o cigarro como drogas lícitas e a maconha e a cocaína como drogas ilícitas 2,21,25,26,27.

Verificou-se que quatro adolescentes eram do sexo feminino e quatro do masculino. Contar com a participação de quatro meninas chama a atenção na medida em que pesquisas realizadas com ado- 


\section{Tabela 1}

Informações sobre os adolescentes.

\begin{tabular}{|c|c|c|c|c|}
\hline Adolescente & Idade (anos) & Sexo & Drogas que já fez uso & Composição familiar \\
\hline A & 12 & Masculino & Maconha, cigarro e álcool & Mãe, irmã e duas tias \\
\hline B & 12 & Masculino & Maconha, cigarro e álcool & Avós, mãe e primo \\
\hline C & 14 & Feminino & $\begin{array}{c}\text { Maconha, cocaína, cigarro e } \\
\text { álcool }\end{array}$ & Pais e irmão \\
\hline D & 17 & Feminino & $\begin{array}{c}\text { Maconha, cocaína, cigarro e } \\
\text { álcool }\end{array}$ & Mãe, padrasto e três imãs \\
\hline E & 18 & Masculino & $\begin{array}{c}\text { Maconha, cocaína, cigarro e } \\
\text { álcool }\end{array}$ & Mãe e padrasto \\
\hline $\mathrm{F}$ & 18 & Masculino & $\begin{array}{c}\text { Maconha, cocaína, cigarro e } \\
\text { álcool }\end{array}$ & Pais e duas irmãs \\
\hline G & 18 & Feminino & $\begin{array}{c}\text { Maconha, cocaína, cigarro e } \\
\text { álcool }\end{array}$ & Mãe e três irmãos \\
\hline $\mathrm{H}$ & 18 & Feminino & $\begin{array}{c}\text { Maconha, cocaína, crack, cigarro } \\
\text { e álcool }\end{array}$ & Mãe, padrasto e irmão \\
\hline
\end{tabular}

lescentes inseridos em CAPSad têm apresentado um número maior de usuários adolescentes do sexo masculino, quando comparados ao sexo feminino 2,21,25,26. É possível que a participação dessas adolescentes neste trabalho indique uma mudança nos processos de inserção de mulheres nos serviços e coloca-se a necessidade de novos estudos serem realizados, buscando investigar mais profundamente as especificidades entre homens e mulheres relacionadas às questões do uso abusivo de álcool e outras drogas, tendo como destaque a população adolescente.

Na Tabela 2, a seguir, apresentam-se informações sobre as internações dos adolescentes em clínicas para tratamento de dependência química.

Os dados apresentados na Tabela 2 revelaram que cinco dos oito adolescentes participantes, anteriormente ou durante a inserção no CAPSad, já passaram por processo de internação em clínicas designadas para tratamento de dependência química e o tempo de permanência nestes locais foi de, pelo menos, seis meses.

O procedimento de internação para crianças e adolescentes está previsto pela RAPS apenas em hospitais gerais para tratar os sintomas agudos, sendo utilizada como procedimento quando todos os outros recursos disponíveis já estiverem sido acionados e não resultaram em ações efetivas 12,15, no entanto, verifica-se uma baixa adesão dos hospitais gerais na concessão destes leitos, o que contribui para que internações em hospitais psiquiátricos continuem sendo realizadas 14,15,16,17,18.

Sobre a permanência desses adolescentes em regime de internação, além da regularidade que parece ocorrer, importa destacar que este tipo de dispositivo de cuidado não se caracteriza como uma medida socioeducativa e tampouco uma medida circunscrita na saúde, desconsiderando, dentre outros elementos, a reconhecida situação peculiar de desenvolvimento da infância e adolescência e os impactos de internações que irão impor privações em diversas esferas como, por exemplo, o direito ao convívio social, familiar e comunitário, conforme previstos pelo ECA.

Aponta-se aqui a escassez de pesquisas que focalizem e envolvam outros métodos de cuidado à população adolescente como, por exemplo, a estratégia de RD, pautada nas políticas públicas como referência de cuidado à população com necessidades em relação ao uso abusivo de drogas. Nessa direção, destaca-se a necessidade de avançar em estudos que envolvam diferentes abordagens e estratégias de cuidado junto à população infanto-juvenil, como também, sobre o concreto envolvimento dos familiares que vivenciam e compartilham deste cuidado.

Compreende-se também a relevância do papel dos familiares e de suas demandas, na medida em que as ações de apoio oferecidas a eles para a sustentação do adolescente nesse processo de cuidado, dentre outras questões, terão implicações relevantes sobre o alcance e efetividade desse percurso. 
Tabela 2

Internações em clínicas para tratamento de dependência química.

\begin{tabular}{lcc}
\hline Adolescente & Número de internações em clínicas para dependência & Tempo de internação (meses) \\
\hline A & Nenhuma & - \\
B & 1 & 6 \\
C & Nenhuma & - \\
D & 1 & 6 \\
E & 1 & 15 \\
F & Nenhuma & - \\
G & 1 & Mínimo de 6 \\
H & 1 & 6 \\
\hline
\end{tabular}

\section{Resultados e discussão advindos das entrevistas com os adolescentes}

\section{- Drogas}

Os adolescentes foram solicitados a falar sobre como entendem a droga em suas vidas e no cotidiano, como pode ser observado nos DSCs a seguir:

"É uma coisa boa e é uma coisa ruim. A droga tem seu lado ruim e seu lado bom. É boa porque dá uma sensação boa, ela me alivia. Por exemplo, a maconha, ela me dá fome e sono, então eu durmo cedo e me alimento bem, então até que faz bem come e dorme, não tem briga, não tem nada. Você fica mais calmo, fica mais leve, você pensa mais, você reflete mais, agora é ruim porque ninguém gosta e fica todo mundo com mau olhado pra você. Também se eu cheiro eu perco a fome e o sono, é onde que eu fico dias acordado é é ruim porque acaba com as coisas dentro de mim, acaba com os neurônios, né".

"Ai uma merda, uma desgraça que acabou com a minha vida. Eu não ia nem pra escola, eu ia na escola às vezes, eu ficava sempre na rua. Aí eu chegava em casa e quebrava tudo e era isso. Bom, não vou mais falar que acabou com a minha vida porque eu tenho muita coisa que fazer ainda lá na frente, mas acabou com o meu passado... Eu podia já ter terminado os estudos, eu podia tá entrando numa faculdade, podia já ter feito muito mais cursos, podia ter me desenvolvido no esporte porque eu queria ser um atleta bem-sucedido. Aí agora que eu fui internada e voltei, agora eu não faço que nem eu fazia antes e eu vejo que eu não ganhei nada com drogas, só ganhei falta de respeito dos outros, só me diminuí, me menosprezei, fiz a minha mãe passar por um desgosto muito grande, minha família. Então, acabou com tudo".

Os discursos indicam que os adolescentes apontam aspectos positivos relacionados ao uso e, também, aspectos negativos. Sobre os aspectos positivos, os adolescentes destacam que as drogas proporcionam sensações prazerosas, de alívio e bem-estar, aumento do apetite e apontam como exemplo a maconha.

Os adolescentes deste estudo revelaram uma relação importante com a maconha, pois acreditam que esta é uma droga natural, pois advém de uma planta e que pode ser menos prejudicial que o cigarro, por exemplo. Já sobre a cocaína, eles julgam que a mesma é mais prejudicial e causa um desejo mais intenso de consumi-la novamente, dentre outros.

Assim, verifica-se o destaque conferido à maconha em relação aos seus aspectos positivos identificados no dia a dia dos mesmos, em detrimento dos efeitos da cocaína, que são considerados negativos, como diminuição do apetite, desregulação do sono e destruição de neurônios.

Os resultados deste trabalho reforçam achados de outras pesquisas com essa população, nos quais os adolescentes correlacionam o uso de drogas a sensações de prazer, relaxamento e diversão, e também ao aumento do apetite 2,25 .

Especificamente em relação ao uso da maconha, tem-se o estudo de Pereira \& Wurfel 28, que sob a perspectiva da $\mathrm{RD}$, buscou conhecer a opinião de usuários de drogas sobre o uso de maconha durante o tratamento para abuso do crack. Os resultados revelaram que segundo os usuários a maconha diminui a fissura causada pelo crack e que não a consideram uma droga prejudicial. 
Observa-se que na literatura há diferentes opiniões em relação ao uso da maconha, que ressaltam os prejuízos ${ }^{29}$, como a diminuição da atenção e memória, ansiedade e paranoia e o uso crônico, que pode causar déficits de aprendizagem, apatia e improdutividade, humor deprimido, dentre outros; e possíveis benefícios, como sensação de relaxamento, euforia, aumento do prazer sexual 30, além de ser uma droga pouco tóxica quando comparada aos outros tipos de drogas 31.

Também observa-se que nos próprios debates no âmbito legislativo sobre descriminalização das drogas há ainda muitas discordâncias sobre o assunto, as quais são pautadas nas experiências de outros países que adotaram a legalização e a não criminalização da maconha para uso pessoal, como Portugal e Uruguai, respectivamente 32,33. Assim, aponta-se a importância de novos estudos serem realizados buscando-se aprofundar sobre o uso da maconha na adolescência, sobre as concepções positivas dos adolescentes e sobre as possibilidades ou não do uso desta substância em ações de RD.

Com base nos DSCs é possível identificar o impacto da droga na vida dos adolescentes, e também compreender mais um aspecto que se soma à complexidade de ações de cuidado que envolve os adolescentes usuários de drogas. No entanto, é possível supor que efetivar essa transformação é ainda mais difícil nessa fase da vida, na qual, além da maturidade ou de ferramentas para lidar com desafios que ainda estão em processo de elaboração e aprendizado, somam-se as vivências de exclusão social e desengajamento como aqui já destacadas.

Assim, constata-se que essa perspectiva deve ser considerada nas práticas de cuidado a essa população, sendo fundamental que os profissionais envolvidos nas ações voltem o olhar para essa questão, pois ela pode auxiliar no planejamento de intervenções com os adolescentes e contribuir para que as ações sejam mais singulares.

\section{- A vida fora do CAPSad}

Em relação ao contexto escolar, dos oito participantes do estudo, quatro frequentavam a escola e os outros quatro não pertenciam mais aos ambientes escolares.

Os adolescentes que frequentavam a escola apresentaram as suas impressões sobre esse contexto em que aspectos positivos e limitações foram avaliados por eles, conforme ilustram os DSCs, a seguir:

"É legal que eu saio de casa um pouco né, vejo minhas amigas e também gosto de conversar com as pessoas da escola".

"Eu não gosto de estudar, de ficar lá o dia inteiro sentado e escrevendo e, além disso, falta muito professor e tem outros que aborrecem porque ficam passando a mesma coisa na lousa, achando que a gente tem cara de idiota".

Já os adolescentes que não estavam vinculados à escola falaram sobre como compreendem sua saída deste contexto, conforme ilustram os DSCs a seguir:

"Eu não gosto de estudar".

"A minha mãe tá tentando arrumar vaga, só".

Em relação aos adolescentes que não frequentam o espaço escolar, pareceu comum em suas falas a autorresponsabilização pela desvinculação do contexto escolar. A responsabilização ao indivíduo e/ ou grupo familiar tem sido debatida e, frequentemente, apontada como artifício para que questões de ordens coletivas e de direito fiquem restritas à esfera singular e, portanto, compreendidas e respondidas pelo viés individual. Assim, questões como a vulnerabilidade social, políticas públicas, processos de exclusão, dentre outras, inerentes e implicadas com a dimensão macrossocial, são minimizadas.

Compreende-se que tal visão, de autorresponsabilização e individualização sobre a realidade vivida, possivelmente soma-se à carga de frustração, ao baixo senso de competência ou de autoestima dos adolescentes e seus familiares que, como se sabe, podem relacionar-se a maiores ou menores chances de enfrentamento dos desafios que estão colocados em seu cotidiano.

Importa destacar que a desvinculação do espaço escolar implica rebatimentos importantes no cotidiano e nas possibilidades de inserção social tanto para o momento presente, quando estão demandando por atenção e por oportunidades de estabelecimento de rotinas e de interação entre pares, quanto em termos futuros, especialmente se são consideradas as oportunidades de engajamento social, qualificação profissional, dentre outros.

Devido à importância reconhecida do contexto escolar em relação ao desenvolvimento, na contribuição da construção e aprimoramento de habilidades, formação da identidade, aperfeiçoamento e 
elaboração de valores, formação educacional e cidadã, dentre muitas outras, aponta-se a importância da efetivação de ações intersetoriais que possam viabilizar a permanência e inserção desses adolescentes nesses espaços que deveriam ser de pertencimento.

Além da escola, os adolescentes falaram sobre como é para eles conviver ou estar em outros contextos fora do CAPSad. Os DSCs revelaram a família como importante fonte de suporte social desses adolescentes, como pode ser observado nos DSCs a seguir:

"Eu me sinto muito querida no lado da minha família, porque eu sei que todo mundo me ama e que é ela que me dá mais força pra permanecer limpa, sem o uso de droga. A minha mãe, por exemplo, apesar de brigar muito, ela me abraça e me beija quando ela tá calma”.

"O relacionamento lá em casa é meio todo mundo se ama. Quando tá tudo calmo, todo mundo brinca e ri, quando tá todo mundo estressado, a gente briga, mas daqui a pouco dá cinco minutos tá todo mundo rindo de novo. É a assim o ambiente lá em casa, é muito um pouco tá lá em baixo, daqui a pouco tá lá em cima. É muito instável".

Sobre o apoio familiar, a literatura aponta que o suporte, o bom relacionamento com filhos, zelo e afetividade oferecidos pela família aos adolescentes são fatores que podem ser protetivos ao uso de drogas 34 . Além disso, estudos têm destacado que o apoio oferecido pela família no tratamento aos adolescentes que fazem uso de drogas é verificado como importante para a adesão do tratamento 2,25 .

Os adolescentes também falaram mais especificamente em relação ao grupo de pares, como amigos e conhecidos, como revela o DSC a seguir:

"Eu não tenho muita amizade agora, primeiro que eu não tô indo na escola e é na escola que a gente faz mais amizade, segundo que eu tô muito mais reservada, eu não tô mais conversando com qualquer um. Amigo pra mim tá difícil fazer por enquanto".

"Normal, depende do amigo né, por exemplo, tem amigo que eu vou só pra usar droga sabe e tem amigo que fica de boa, só conversando, toma guaraná, conversa”.

Os DSCs revelam não só sobre a ausência de amigos, de oportunidades de encontros e de preconceitos, como também sobre os desafios implicados na tentativa do distanciamento das drogas e seu atrelamento aos relacionamentos associados ao uso. Nesse sentido, os resultados deste estudo reforçam achados de pesquisas que têm apontado sobre os vínculos fortalecidos com amigos que também fazem uso de drogas e a dificuldade dos adolescentes usuários em tecer novos relacionamentos distanciados da droga 2,25,26.

Esses resultados reforçam as considerações sobre a crescente desvinculação dos adolescentes das oportunidades de relacionamentos e inserção social, ou seja, a crescente exclusão social que se processa, como uma bola de neve, nos diferentes contextos da vida cotidiana.

O reconhecimento da exclusão como processo reforça a premência de considerar que as ações de atenção e cuidado desenvolvidas pelos CAPSad a adolescentes devem focar esforços na ampliação das redes sociais, do uso do território em seus diferentes contextos, na concreta dimensão da inclusão social 35 .

\section{- O CAPSad}

Ao falarem sobre o momento de chegada ao CAPSad, os adolescentes expressaram não gostar e não compreender o que fariam no serviço, além de outros sentimentos, conforme revelam os DSCs a seguir:

"Quando eu cheguei aqui, no começo, eu odiei dona, eu não queria vir, eu vinha por obrigação".

"Eu fiquei com vergonha das pessoas que tinham aqui, mas eu acho que foi vergonha de mim mesmo".

Os resultados permitem compreender como o momento de chegada e as impressões iniciais do serviço podem ser fundamentais para a permanência e aderência no mesmo. Assim, importa reforçar a relevância do acolhimento, que muito além de um primeiro contato do adolescente com o serviço, pode ser ferramenta fundante e representa uma potência para a efetivação do cuidado.

Em consonância com essas considerações, ainda que focalizando a população adulta, estudos apontam a importância do acolhimento no cuidado aos usuários de drogas e colocam a necessidade de ser realizado no momento em que o usuário busca o serviço, pois considerando que esta população apresenta muitas oscilações em relação ao tratamento e muitas vezes encontra-se em diversas situações de vulnerabilidade, pode não retornar mais ao serviço 36. 
Em relação às atividades realizadas pelos adolescentes no serviço e se as mesmas ajudam no dia a dia, os adolescentes apontam o que gostam e o que não gostam, como pode ser observado nos DSCs a seguir:

"Eu gosto de vir aqui, de ir no grupo, porque é um horário que eu tenho pra conversar sobre o dia a dia, contar as coisas que tão dentro de mim, pra desabafar tudo que fica guardado e isso me faz bem, faz eu me expressar. Muitas coisas eu sinto que eu posso falar aqui, porque são pessoas seguras, que não vão sair falando pra ninguém, coisas que eu não tenho como falar com a minha mãe, já que eu sou muito fechada com ela porque ela não vai entender e pessoas lá fora também vão entender de outro jeito. Eu gosto mesmo de contar as coisas, pra não ficar preso aqui dentro porque machuca viu, fala sério".

"O que eu menos gosto é de ficar tomando remédio porque me deixa às vezes meio retardada, me dá sono na hora errada, às vezes perdia a fome também”.

Destaca-se, assim, o papel do CAPSad na vida desses adolescentes que se dá em meio a tantas situações de exclusão e de ausência de apoios. Tal relevância pode ser reforçada ao considerarmos as opiniões dos adolescentes sobre um serviço ainda bastante limitado nas ações de atenção e cuidado a adolescentes, em que se pressupõe que tais benefícios seriam ainda maiores caso melhor cuidado fosse disponibilizado.

Alguns adolescentes também pontuaram ações realizadas pelo serviço que consideram negativas, como ir ao médico e tomar medicamentos devido aos efeitos adversos destas medicações, como sono e perda de apetite. Ainda que não se tenha aqui a intenção de problematizar sobre o uso da medicação, reforça-se a necessidade de ações que contextualizem e esclareçam o uso desse recurso tanto para os adolescentes quanto para os seus familiares.

Sugere-se também ações de compartilhamento de informações entre profissionais, adolescentes e familiares, tendo os usuários e familiares como coparticipantes na definição das ações de cuidado, o que poderia favorecer tanto o comprometimento e responsabilização pelo próprio cuidado, como também a eficácia dos dispositivos de intervenções.

\section{Considerações finais}

Este estudo objetivou compreender o cotidiano dos adolescentes em relação às drogas, o CAPSad e os demais contextos de inserção pelos quais transitam, buscando dar voz aos adolescentes. Para tanto, a opção pela observação participante viabilizou o contato e a vinculação do pesquisador no contexto de estudo e, em especial, com os adolescentes participantes no contato cotidiano com os mesmos no serviço.

Ainda que se tenha claro que parte da realidade desses adolescentes e do serviço focalizado neste trabalho se repita, reconhece-se que a inserção em apenas um dispositivo limite a generalização dos achados.

Compreende-se que o estudo acrescenta ao dar voz aos adolescentes, ao identificar e compreender sobre as drogas e as particularidades de seus cotidianos, segundo suas próprias perspectivas, dentro e fora do serviço.

Os resultados evidenciaram que esses adolescentes vivenciam um processo de exclusão social e desengajamento em diversas esferas, aqui destacados o contexto escolar e, em alguma medida, o contexto familiar e o território onde vivem.

Também verificou-se a percepção dos adolescentes sobre as drogas em suas vidas, que rebatem na reflexão sobre estratégias de cuidado, como a estratégia de $\mathrm{RD}$ e de possibilidades de engajamento e in(ex)clusão social.

Nesse sentido, considera-se fundamental dar foco às ações de promoção e prevenção relacionadas ao uso de drogas, voltadas aos adolescentes e familiares, que devem ser planejadas e executadas não em uma posição de repressão e combate, usualmente utilizada, mas sim com informações de acordo com a realidade desses sujeitos, e principalmente com o envolvimento e participação dos adolescentes, familiares e profissionais de diversos serviços, nos diferentes setores, como educação, saúde, assistência social, judiciário, cultura, dentre outros. 


\section{Colaboradores}

C. C. Galhardi foi responsável pela concepção do projeto, redação, revisão e finalização do artigo. T. S. Matsukura orientou a elaboração do projeto, redação, revisão e finalização do artigo.

\section{Agradecimentos}

À Capes pelo apoio financeiro.

\section{Referências}

1. Departamento de Ações Programáticas Estratégicas, Secretaria de Atenção à Saúde, Ministério da Saúde. Caminhos para a política de saúde mental infanto-juvenil. Brasília: Ministério da Saúde; 2005

2. Vasters GP, Pillon SC. O uso de drogas por adolescentes e suas percepções sobre adesão e abandono de tratamento especializado. Rev Latinoam Enferm 2011; 19:1-8.

3. Kessler F, von Diemen L, Seganfredo AC, Brandão I, Saibro P, Scheidt B, et al. Psicodinâmica do adolescente envolvido com drogas. Rev Bras Psiquiatr 2003; 25 Suppl 1:33-41.

4. Galduróz JCF, Noto AR, Fonseca AM, Carlini EA. V levantamento nacional sobre o consumo de drogas psicotrópicas entre estudantes do ensino fundamental e médio da rede pública de ensino nas 27 capitais brasileiras. Brasília: Centro Brasileiro de Informações sobre Drogas Psicotrópicas; 2004.

5. Machado LV, Boarini ML. Políticas sobre drogas no Brasil: a estratégia de redução de danos. Psicol Ciênc Prof 2013; 33:580-95.

6. Machado AR, Miranda PSC. Fragmentos da história da atenção à saúde para usuários de álcool e outras drogas no Brasil: da Justiça à Saúde Pública. Hist Ciênc Saúde-Manguinhos 2007; 14:801-21.

7. Taño BL, Matsukura TS. Saúde mental infanto-juvenil e desafios do campo: reflexões a partir do percurso histórico. Cad Ter Ocup UFSCar 2015; 23:439-47.

8. Amarante P. Psiquiatria social e reforma psiquiátrica. Rio de Janeiro: Editora Fiocruz; 1994.

9. Couto MCV. Política de saúde mental para crianças e adolescentes: especificidades e desafios da experiência brasileira (2001-2010) [Tese de Doutorado]. Rio de Janeiro: Universidade Federal do Rio de Janeiro; 2012.

10. Departamento de Atenção Especializada e Temática, Secretaria de Atenção à Saúde, Ministério da Saúde. Fórum Nacional de Saúde Mental Infanto-juvenil: recomendações de 2005 a 2012. Brasília: Ministério da Saúde; 2014.

11. Secretaria de Atenção à Saúde, Ministério da Saúde. A política do Ministério da Saúde para atenção integral a usuários de álcool e outras drogas. 2a Ed. Brasília: Ministério da Saúde; 2004.

12. Ministério da Saúde. Portaria no 3.088, de 23 de dezembro de 2011. Institui a Rede de Atenção Psicossocial para pessoas com sofrimento ou transtorno mental e com necessidades decorrentes do uso de crack, álcool e outras drogas, no âmbito do Sistema Único de Saúde. Diário Oficial da União 2011; $30 \mathrm{dez}$.

13. Taño BL, Matsukura TS. Os centros de atenção psicossocial infanto-juvenis: características organizacionais e oferta de cuidados. Rev Ter Ocup 2014; 25:208-16. 
14. Scisleski ACC, Maraschin C, Silva RN. Manicômio em circuito: os percursos dos jovens e a internação psiquiátrica. Cad Saúde Pública 2008; 24:342-52.

15. Ministério da Saúde; Conselho Nacional do Ministério Público. Atenção psicossocial a crianças e adolescentes no SUS: tecendo redes para garantir direitos. Brasília: Ministério da Saúde/Conselho Nacional do Ministério Público; 2014.

16. Costa PHA, Mota DCB, Paiva FS, Ronzani TM. Desatando a trama das redes assistenciais sobre drogas: uma revisão narrativa da literatura. Ciênc Saúde Coletiva 2015; 20:395-406.

17. Andrade TM. Reflexões sobre políticas de drogas no Brasil. Ciênc Saúde Coletiva 2011; 16:4665-74.

18. Santos VE, Soares CB, Campos CMS. Redução de danos: análise das concepções que orientam as práticas no Brasil. Physis (Rio J.) 2010; 20:995-1015.

19. Barcellos-Oliveira MFAP, Muylaert CJ, Bastos IT, Reis AOA. Processos de trabalho e impasses institucionais em saúde mental. In: Reis AOA, Fonseca FL, Rolim Neto ML, Delfini PSS, organizadores. As crianças e os adolescentes dos Centros de Atenção Psicossocial Infanto-juvenil. São Paulo: Schoba; 2012. p. 165-79.

20. Raupp L, Sapiro CM. Reflexões sobre concepções e práticas contemporâneas das políticas públicas para adolescentes: o caso da drogadição. Saúde Soc 2005; 14:60-8.

21. Araújo NB, Marcon RS, Silva NG, Oliveira JRT. Perfil clínico e sociodemográfico de adolescentes que permaneceram e não permaneceram no tratamento em um CAPSad de Cuiabá/MT. J Bras Psiquiatr 2012; 61:227-34.

22. Minayo MCS, Deslandes SF, Gomes R. Pesquisa social: teoria, método e criatividade. 29a Ed. Petrópolis: Editora Vozes; 2008.

23. Lefevre F, Lefevre ANC. Pesquisa de representação social: um enfoque qualiquantitativo à metodologia do discurso do sujeito coletivo. v. 20. Brasília: Líber Livro; 2010.

24. Lefevre AMC, Crestana MF, Cornetta VK. A utilização da metodologia do discurso do sujeito coletivo na avaliação qualitativa dos cursos de especialização "Capacitação e Desenvolvimento de Recursos Humanos em SaúdeCADRHU”, São Paulo - 2002. Saúde Soc 2003; 12:68-75.

25. Almeida MM. A adesão de adolescentes ao tratamento para o uso de álcool e outras drogas: um bicho de sete cabeças [Dissertação de Mestrado]. São Paulo: Escola de Enfermagem, Universidade de São Paulo; 2010.
26. Mancilha GBA. Permanência de adolescentes em CAPSad - um olhar para a vulnerabilidade [Dissertação de Mestrado]. São Paulo: Escola de Enfermagem, Universidade de São Paulo; 2015.

27. Malbergier A, Cardoso LRD, Amaral RA. Uso de substâncias na adolescência e problemas familiares. Cad Saúde Pública 2012; 28:678-88.

28. Pereira AS, Wurfel RF. O uso de maconha como estratégia de redução de danos em dependentes de crack. Aletheia 2011; 34:163-74.

29. Oliveira MS, Rigoni MS, Susin N, Bortolini M, Dornelles CG, Zanetello LB. A percepção de adolescentes usuários e não usuários de maconha sobre problemas de comportamento. SMAD Rev Eletrônica Saúde Mental Álcool Drog 2012: 8:134-41.

30. Rigoni MS, Oliveira MS, Andretta I. Consequências neuropsicológicas do uso da maconha em adolescentes e adultos. Ciência e Cognição 2006; 8:118-26.

31. Nery AF. Por que os humanos usam drogas? In: Nery AF, Macrae E, Tavares LA, Nuñez ME, Rêgo M, organizadores. As drogas na contemporaneidade: perspectivas clínicas e culturais. Salvador: EDUFBA; 2012; p. 11-20.

32. Valério ALR. A redução de riscos e danos na saúde mental através do CAPSad. In: Almeida Filho N, organizador. As drogas na contemporaneidade: perspectivas clínicas e culturais. Salvador: EDUFBA; 2012. p. 209-22.

33. Fiori M, Tófoli LF. Dossiê descriminalização STF 2a edição: argumentos pela criminalização e evidências científicas. São Paulo: Plataforma Brasileia de Políticas de Drogas; 2015.

34. Schenker M, Minayo MCS. Fatores de risco e de proteção para o uso de drogas na adolescência. Ciênc Saúde Coletiva 2005; 10:707-17.

35. Salles MM, Barros S. Relações do cotidiano: a pessoa com transtorno mental e sua rede de suporte social. Physis (Rio J.) 2011; 21:561-79.

36. Andrade AT, Sousa MLT, Quinderé PHD. Acolhimento no Centro de Atenção Psicossocial para álcool e outras drogas: concepções dos trabalhadores de saúde. Pesqui Prát Psicossociais 2013 ; 8:166-75. 


\section{Abstract}

This study aimed to shed light on the daily reality of adolescents in relation to drugs, at a Center for Psychosocial Care for Alcohol and Other Drugs (CAPSad) and the other contexts in which they circulate, analyzed from their own perspective. The study included eight adolescents 12 to 18 years of age enrolled in the CAPSad in a medium-sized city in the interior of São Paulo State, Brazil. Data collection used an identification form for the adolescents and family network and a semi-structured interview. Data analysis used the collective subject discourse (CSD) technique. The results show that adolescents experience a process of social exclusion and disengagement in various spheres of life, and highlights the CAPSad as an important space in their day-to-day life, although limited in its care for these youngsters. The study's contributed by giving a voice to these adolescents, a group frequently excluded from treatment and outreach services for drug users, as well as identifying and shedding light on the drugs and the specificities of their day-to-day lives, from their own perspective both inside and outside the clinic.

Substance-Related Disorders; Activities of Daily Living; Mental Health; Adolescent

\section{Resumen}

El objetivo de este estudio fue comprender el día a día cotidiano de adolescentes, respecto al consumo de drogas, en un Centro de Atención Psicosocial de Alcohol y otras Drogas (CAPSad), y en los demás contextos de inserción por los que se mueven, desde la óptica de los propios adolescentes. Se contó con la participación de ocho adolescentes con edades comprendidas entre 12 y 18 años, vinculados al CAPSad, de un municipio de tamaño medio en el interior del estado de São Paulo, Brasil, donde se realizó el estudio. Para la recogida de datos se utilizó un formulario de identificación de los adolescentes, su red familiar, y un guion de entrevista semiestructurada. Para el análisis de los datos se adoptó la técnica del Discurso del Sujeto Colectivo (DSC). Los resultados muestran que los adolescentes viven un proceso de exclusión social y desconexión en diversas esferas de la vida y destaca el CAPSad, como un espacio importante en su día a día, aunque limitado en lo que se refiere a las acciones de atención y cuidado a los adolescentes. Este estudio aporta el dar voz a los adolescentes, población que frecuentemente está excluida de los servicios destinados a la acogida y combate al consumo de drogas, así como también al proceso de identificación y comprensión sobre consumo de drogas y particularidades de su día a día, según sus propias perspectivas, dentro y fuera de este servicio social.

Trastornos Relacionados con Sustancias; Actividades Cotidianas; Salud Mental;

Adolescente
Recebido em 26/Ago/2016

Versão final reapresentada em 24/Jul/2017 Aprovado em 27/Jul/2017 